\title{
An epidemiology of paediatric cervical spine injuries at the Red Cross War Memorial Children's Hospital over a ten-year period
}

\author{
Noconjo $L^{1} \mathbb{B}$, Horn $A^{2}$ \\ 1 B Physio, MBChB(UKZN); Registrar, Orthopaedic Surgery (UCT) \\ $2 \mathrm{MBChB}($ Pret), FC Orth(SA), MMed(UCT)Ortho; Consultant orthopaedic surgeon
}

Department of Orthopaedic Surgery, Faculty of Health Sciences, Groote Schuur Hospital and University of Cape Town, South Africa

Corresponding author: Dr L Noconjo, Department of Orthopaedic Surgery, Faculty of Health Sciences, Room $49 \mathrm{H}$ floor, Old Main Building, Groote Schuur Hospital, 7701; tel: 0837511356: email: lubabalonoconjo@gmail.com

\begin{abstract}
Background: Paediatric cervical spine injury (CSI) is rare compared to adult CSI. Very little has been published regarding the epidemiology and outcome of CSI in children in South Africa. The objective of this retrospective study is to characterise the epidemiology and report on the outcome of CSI in children $<13$ years at a tertiary referral centre for paediatric trauma.

Methods: We performed a retrospective study of CSI at our hospital over a ten-year period. The Picture Archiving and Communication System (PACS) of our institution was searched for patients with CSIs. Search terms included: cervical spine fracture, subluxation, dislocation, contusion, SCIWORA (spinal cord injury without radiographic abnormality) and retroclival haematoma. Demographic and clinical data were obtained from hospital records. Injury-related variables were compared for children $\leq 8$ and $>8$ years due to anatomical and biomechanical differences observed. Outcome was assessed using the Frankel grading.

Results: Sixty-six children were identified with a cumulative incidence of $0.1 \%$. The median age was 7 years (inter-quartile range $4-8.8$ ) and $65 \%$ were male. All injuries were caused by blunt trauma. Passenger motor vehicle injury (MVA) accounted for $52 \%$ of injuries. Injuries due to physical abuse, and recreational and sporting activities did not occur. Children $\leq 8$ years of age incurred more injuries than those $>8$ years $(74.2 \%$ vs $25.8 \%)$. Ninety-eight per cent of injuries occurred in the upper cervical spine (C1-C4) of children $\leq 8$ years. Of the $13(19.6 \%)$ children with neurologic injury, five (7.5\%) had complete spinal cord injury, four (6\%) had incomplete neurology, and three (4.5\%) died. SCIWORA occurred in six (9\%) children with variable outcome. Seven patients (10.6\%) were operated for instability. An injury severity score (ISS) of 25 (13-34) was associated with poor outcome. The mortality rate was $4.5 \%$ and all children who died were $\leq 8$ years with upper CSIs and closed head injuries (CHIs) related to MVA.

Conclusion: CSI occurred in $0.1 \%$ of patients evaluated following trauma. MVAs, either pedestrian or passenger, were responsible for the majority of these injuries. Children $\leq 8$ years were more frequently injured and sustained injuries to the upper cervical spine. The majority of paediatric CSIs are stable injuries that can be managed conservatively; however, urgent surgical stabilisation is indicated for unstable injuries. CSI with associated $\mathrm{CHI}$ caused by MVAs in young children is associated with death. Even though our patients are referred from high violence communities, no CSIs were attributed to physical abuse or penetrating injury.
\end{abstract}

Level of evidence: Level 4

Keywords: cervical spine injury, motor vehicle accident, Frankel grade, head injury

Citation: Noconjo L, Horn A. An epidemiology of paediatric cervical spine injuries at the Red Cross War Memorial Children's Hospital over a ten-year period. SA Orthop J 2020;19(1):18-22. http://dx.doi.org/10.17159/2309-8309/2020/v19n1a2

Editor: Dr J Davis, Stellenbosch University, Cape Town, South Africa

Received: June 2019 Accepted: September $2019 \quad$ Published: March 2020

Copyright: $\odot 2020$ Noconjo L. This is an open-access article distributed under the terms of the Creative Commons Attribution Licence, which permits unrestricted use, distribution and reproduction in any medium, provided the original author and source are credited.

Funding: No funding was received for this study.

Conflict of interest: The authors have no conflicts of interest to declare. 


\section{Introduction}

Paediatric cervical spine (C-spine) injury (CSI) is serious yet relatively uncommon, occurring in less than $1 \%$ of all children evaluated following blunt trauma. ${ }^{1}$ In the paediatric population as a whole, spinal cord injuries occur far less frequently than in adults. ${ }^{2}$ CSIs account for $30-40 \%$ of spinal trauma in adults, but in children $80 \%$ of vertebral injuries occur in the C-spine. ${ }^{3}$

The anatomy of the immature $\mathrm{C}$-spine predisposes it to injuries which do not occur in the adult population. The paediatric spine is characterised by increased elasticity of the interspinous ligaments, posterior joint capsule and cartilaginous end plates. Wedgeshaped vertebral bodies and the horizontal orientation of the facet joints may predispose children to upper CSIs. ${ }^{3}$ Children $\leq 8$ years have relatively larger and heavier heads in relation to the body, which shifts the fulcrum of movement to the upper $\mathrm{C}$-spine with the maximum movement at $\mathrm{C} 2 / \mathrm{C} 3$. This explains the epidemiological finding that most of the spinal injuries occur between $\mathrm{C} 0$ and $\mathrm{C} 2$ in young children whereas older children, like adults, more commonly sustain injuries in the sub-axial C-spine. ${ }^{4}$ By the age of 8 years, the $\mathrm{C}$-spine is nearing maturity and the injury profile is similar to that of an adult. In this study, we take anatomical and biomechanical differences into account and have divided children into young (0-8 years) and older (8-12 years) groups.

Most paediatric CSIs are as a result of blunt trauma. In South Africa the road traffic mortality rate overall in 2011 was 33.2 per 100000 population. Road traffic accidents are one of the leading causes of child injury deaths in South Africa, and in Cape Town road traffic injuries are the leading cause of death in children aged 5-14 years, significantly above the HIVIAIDS mortality rate. ${ }^{5}$ Our institution's trauma unit processes approximately 1200 victims of road traffic injuries per year, yet little is known about the true incidence and severity of CSI in children. Other common mechanisms of injury include falls from a height and contact sports. In the international literature, sporting injuries are the second most common reported mechanisms of injury, although these studies usually include patients up to 18 years of age. ${ }^{6}$

We conducted an epidemiological study in order to characterise $\mathrm{CSI}$ at a tertiary referral centre for paediatric trauma, and to report on the incidence, nature and outcome of CSI in paediatric patients in the South African population.

\section{Methods}

We performed a retrospective study of paediatric CSIs treated at our institution from 2008 to 2017 . Approval of the study was obtained from the institution's Human Research Ethics Committee. All records and radiological investigations of patients seen from 2008 to 2017 with CSI, including isolated cord injuries and intra-spinal haematomas, were reviewed. Patients with inadequate medical or radiological records were excluded, as were those patients with non-traumatic causes for spinal cord compromise.

The Picture Archiving and Communication System (PACS) of our institution's radiological services was searched for patients with CSIs as the diagnosis is invariably confirmed by radiology. Search terms included: cervical spine fracture, subluxation, dislocation, contusion, SCIWORA (spinal cord injury without radiographic abnormality) and haematoma. Patient demographics, date and cause of injury, type and level of injury and outcome data were obtained from hospital records. Outcomes were defined by the Frankel grading system. ${ }^{7}$ Patients were divided into those $\leq 8$ years and those $>8$ years of age, based on anatomical and biomechanical differences in the cervical spine. ${ }^{8}$ Our institution accepts patients up to the age of 13 years from the local community, public and private hospitals that are within its drainage area, and any other child deemed to require subspecialist polytrauma management or neurosurgical intervention. The severity of associated injuries was categorised according to the paediatric injury severity score (ISS) which predicts the morbidity and mortality risk. ISS was calculated from a combination of the abbreviated injury score (AIS). The body was divided into six areas: head or neck, face, thorax, abdomen, extremities and external. Every injury was identified and the most severe in each of the areas was identified. ISS is the sum of the squares of these injuries ranging from 1-75. By convention, a score of $1-8$ is considered minor, 9-16 moderate and $>16$ severe. An ISS of $>41$ indicates a very severe injury with significant risk of mortality.

Data was analysed using Microsoft Excel for Office 365. Descriptive statistics were reported using standard nomenclature for non-parametric data.

\section{Results}

We identified 74 patients that had a radiologically confirmed CSI during the study period. Eight patients were excluded due to inadequate records being available. Our study is based on the remaining 66 patients.

The median age of our patients was 7 years (IQR 4-8.8) (Figure I); $43(65 \%)$ of the patients were males with a male to female ratio of $2: 1$.

All injuries were caused by blunt trauma. The most common mechanism of injury (MOI) was passenger $(n=34$ [52\%]) and

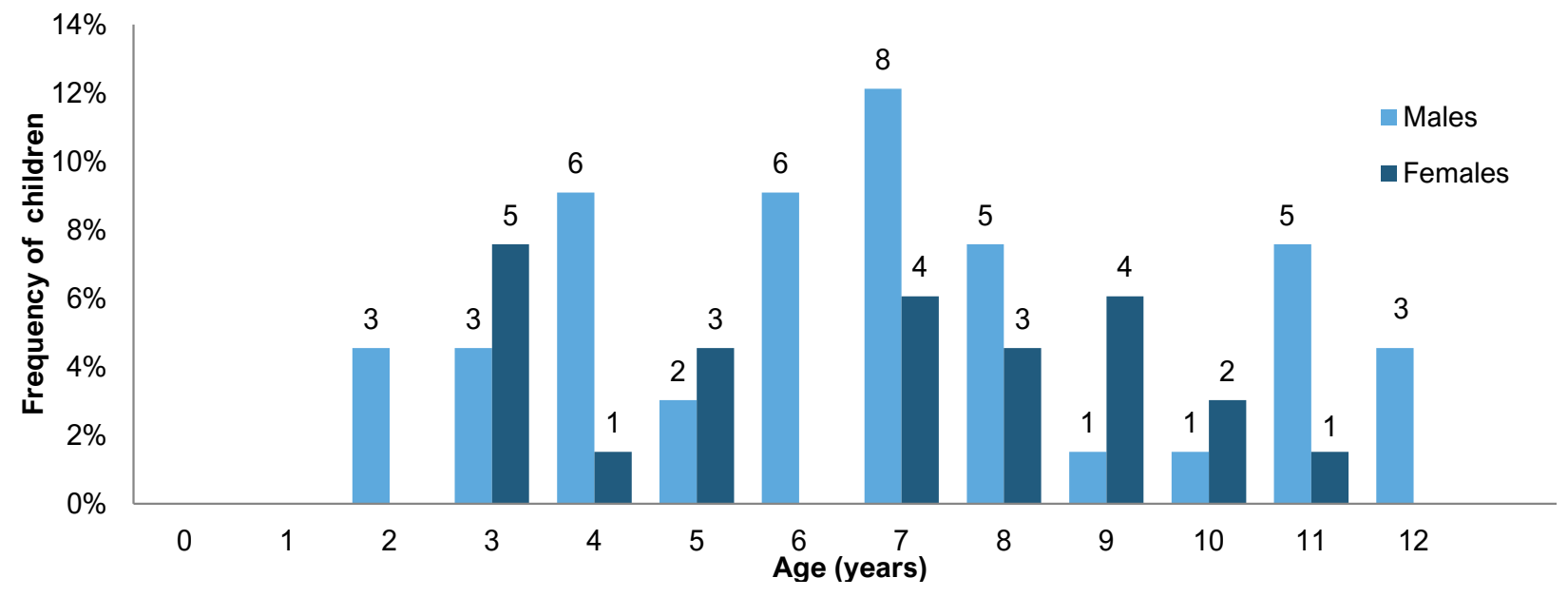

Figure 1. Age distribution of children with CSls by sex 


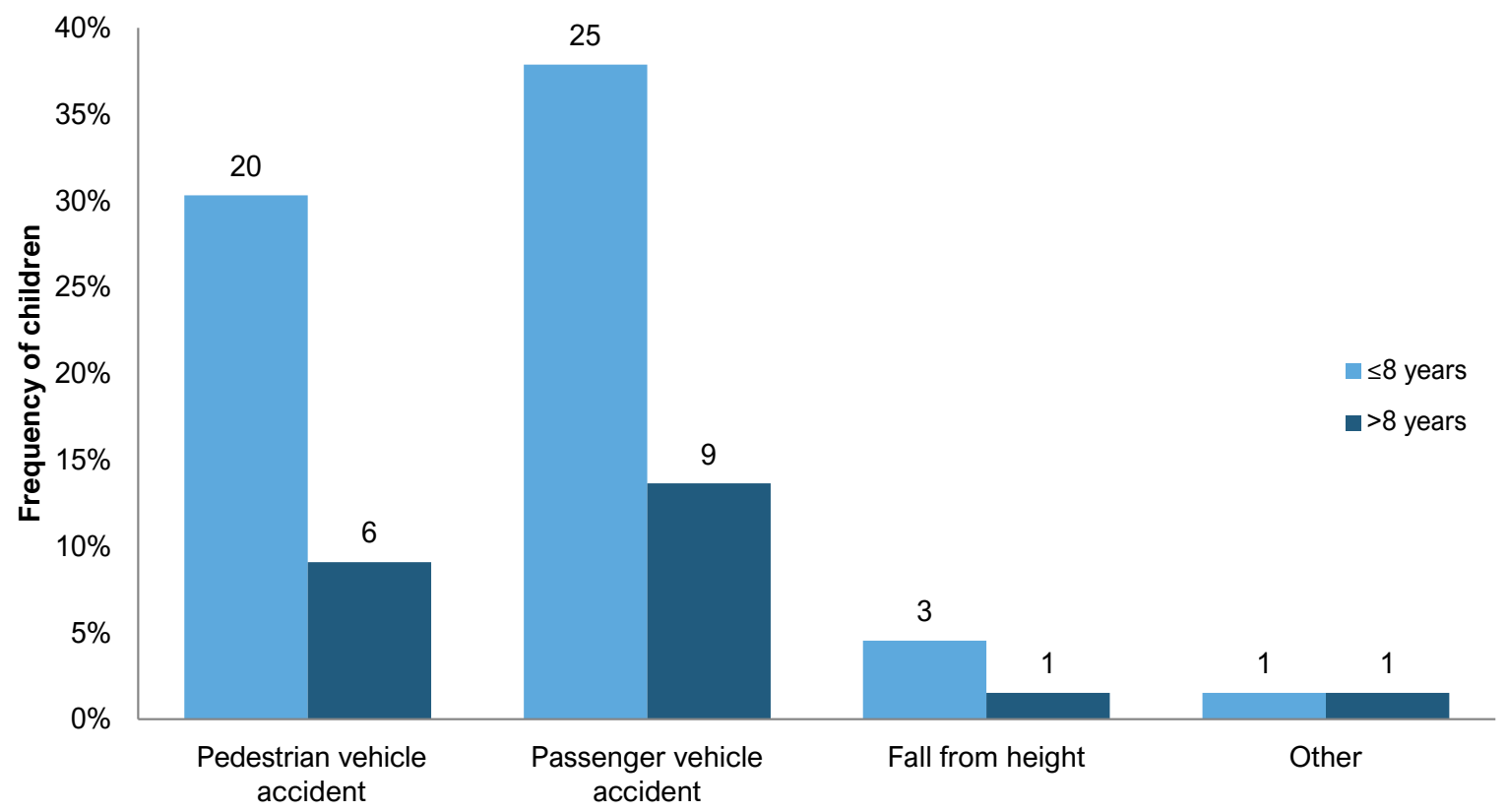

Mechanism of injury

Figure 2. Mechanism of injury according to age group

Table I: Types of injury and age

\begin{tabular}{|l|c|c|c|}
\hline \multicolumn{1}{|c|}{ Type of injury } & All & $<\mathbf{8}$ years & $>8$ years \\
\hline Fracture without SCI & $\mathrm{n}(\%)$ & $\mathrm{n}(\%)$ & $\mathrm{n}(\%)$ \\
\hline Retroclival haematoma & $18(27)$ & $11(17)$ & $7(11)$ \\
\hline Ligamentous injury & $17(26)$ & $11(17)$ & $6(9)$ \\
\hline Atlanto-occipital dissociation & $9(14)$ & $8(12)$ & $1(1)$ \\
\hline SCIWORA & $10(15)$ & $9(14)$ & $1(2)$ \\
\hline Subluxation & $6(9)$ & $6(9)$ & $0(0)$ \\
\hline Fracture with SCI & $5(8)$ & $4(5)$ & $1(2)$ \\
\hline Total & $1(1)$ & $0(0)$ & $1(1)$ \\
\hline
\end{tabular}

SCl: spinal cord injury

pedestrian $(n=26$ [39\%]) MVAs. Falls from a height (4 [6\%]) and other, unspecified causes (2 [3\%]) accounted for the rest. There was no information available on the usage of restraining safety mechanisms. None of the injuries reported were a result of physical abuse, or recreational or sporting activities (Figure 2).

Various patterns of injuries occurred mostly in young patients, with fracture without spinal cord injury $(\mathrm{SCl})$ being the most common injury. The distribution of these injuries for two age groups is depicted in Table $I$.

Of the 17 patients with retroclival haematoma, 16 had no associated ligament injury. One patient had superior tectorial membrane injury; however, subsequent flexion-extension X-rays did not demonstrate cervical instability.

Most injuries occurred in the upper C-spine of the younger group. There was only one patient in this cohort who sustained an injury to the lower C-spine (Table II).

Fifty-seven patients (77.3\%) had associated closed head injuries $(\mathrm{CHI})$. The next most common injuries were long bone fractures (34.8\%), blunt chest trauma $(27.7 \%)$ and blunt abdominal trauma $15(22.7 \%)$. The median ISS was 25 (IQR 13-34) and 8 (IQR 1-16) for children that sustained fatal injuries and for those who survived, respectively.

Patients with stable CSIs were treated conservatively with immobilisation: $56(85 \%)$ in a soft collar and three (4.5\%) with a
Table II: Level of spinal cord injury

\begin{tabular}{|l|c|c|c|}
\hline $\begin{array}{c}\text { Level of C-spine } \\
\text { injuries }\end{array}$ & All ages & 0-8 years & 8-12 years \\
\hline & $n(\%)$ & $n(\%)$ & $n(\%)$ \\
\hline Upper C-spine C1-C4 & $65(98)$ & $48(73)$ & $17(26)$ \\
\hline Lower C-spine C5-C7 & $1(2)$ & $1(1)$ & $0(0)$ \\
\hline Total & $\mathbf{6 6 ( 1 0 0 )}$ & $\mathbf{4 9 ( 7 4 )}$ & $\mathbf{1 7}(\mathbf{2 6})$ \\
\hline
\end{tabular}

hard collar. Seven patients (10.6\%) with unstable CSIs required operative intervention in the form of open reduction and internal fixation. These were all younger children with upper CSIs. One patient underwent anterior fusion and six patients had posterior fusion. The indications for and outcome of surgery are listed in Table III. There was no deterioration of neurological status following surgery in any patient.

Patients with SCIWORA showed variable neurology (one Frankel $A$; four Frankel $C$ and one Frankel $C$ improved to $E$ ). Four patients had residual neurological deficit but were associated with significant $\mathrm{CHI}$.

Quadriparesis (Frankel A) occurred in four other patients. Three of the four patients had associated C-spine instability with subsequent surgical stabilisation. One patient with cervical spinal cord transection at C7/T1 (Frankel A) had a stable $\mathrm{C}$-spine and was treated conservatively with a soft collar.

The overall mortality rate was $4.5 \%$. The three patients who died were admitted following MVAs (two passengers and one pedestrian). They were between the ages of 3 and 5 years. Two patients sustained cervical spinal cord transection at $\mathrm{C} 0 / \mathrm{C} 1$ and $\mathrm{C} 1 / 2$ respectively and all had associated severe $\mathrm{CHI}$.

\section{Discussion}

The cumulative incidence of CSI in our patients was $0.1 \%$. This is less than the published incidence of $1-2.2 \%$ following blunt trauma. ${ }^{1,6}$ Forty-nine patients $(66 \%)$ in our cohort were under the age of 8 years, and there was male preponderance with a male to female ratio of 2:1. In contrast to this, Brown et al. in their review, 
Table III: Details of surgical intervention

\begin{tabular}{|c|l|l|l|}
\hline Patient & \multicolumn{1}{|c|}{ Injury type } & \multicolumn{1}{c|}{ Type of surgery } & \multicolumn{1}{c|}{ Outcome } \\
\hline 1 & Atlanto-occipital dissociation & C0-C2 posterior fusion & Quadriplegia \\
\hline 2 & Atlanto-occipital subluxation & C0-C2 posterior fusion & Quadriplegia \\
\hline 3 & Atlanto-axial dissociation & C0-C2 posterior fusion & No neurology \\
\hline 4 & C2/3 fracture subluxation & C2-C4 anterior fusion & No neurology \\
\hline 6 & C3/4 unifacet dislocation & C3-C4 posterior fusion & Hemiparesis \\
\hline 7 & Dens fracture type 2 + transverse ligament injury & C1-C2 posterior fusion & No neurology \\
\hline & Dens fracture type 2 + transverse ligament injury & C1-C2 posterior fusion & No neurology
\end{tabular}

found that $66 \%$ of their patients were between 9 and 19 years of age. They had a male to female ratio of 1.6:1. ${ }^{6}$ This difference can be explained by the fact that our institution only treats patents up to the age of 13 years, as opposed to 18 years.

MVAs, which account for $48-61 \%$ of all injuries, are the most common mechanism of injury in children both older and younger than 8 years. ${ }^{9}$ Patel et al. showed that $61 \%$ of injuries resulted from MVAs and occupants were found to be unrestrained in $61 \%$ of cases. ${ }^{10}$ In our study, passenger MVAs were responsible for $52 \%$ and $26 \%$ of injuries in the younger and older age groups respectively. Information on the usage of seat belts/child safety seats was not available for our study. The literature clearly documents the effectiveness of safety belts and child safety seats in reducing CSIs in children involved in MVAs. ${ }^{11}$

In the pedestrian subgroup, the majority (73.5\%) of patients were $\leq 8$ years and had a male preponderance. This could be explained by the fact that boys are naturally more risk-seeking than girls, yet the lack of supervision while children are on the street is alarming.

Falls occurred in only four patients (6\%) and were associated with less serious injuries and no neurological sequelae. All these children either fell from caregivers' arms or from a bed, and they were $<1$ year of age. In the published literature, falls account for $11-18 \%$ of CSIs, ${ }^{6,10}$ which is higher than in our population. This may be due to our only including patients with radiologically confirmed CSIs.

Although not classically associated with child abuse, CSI may occur and should not be overlooked. It has been estimated that $1 \%$ of children who suffer non-accidental head injuries also have co-existing spinal trauma. ${ }^{12}$ Rooks et al. reported two cases of child abuse with CSIs and classical radiographic evidence of abuse at multiple sites in the axial and appendicular skeleton..$^{13}$ It is worth noting that in our series there were no CSIs that resulted from physical abuse.

Sporting injuries account for up to $27 \%$ of paediatric CSIs in other published series, ${ }^{1,6,14}$ although this is mostly in the pre-adolescent and adolescent population.

In our population, $98 \%$ of injuries occurred in the upper $\mathrm{C}$-spine. This is consistent with other published series. McCall et al. reported that children under 9 years of age usually have upper CSIs whereas older children, whose biomechanics more closely resemble those of adults, are prone to lower CSIs. ${ }^{8}$ Kokoska et al. in a retrospective study of 408 children who suffered blunt trauma, found that younger ( $\leq 10$ years of age) children sustained high (C1-C4) injuries as compared to their older counterparts who sustained low (C5-C7) CSI (85.3\% versus 56.9\%). ${ }^{15}$

Fractures, with or without $\mathrm{SCl}$ were the most frequently observed injury pattern in both age groups, accounting for $31 \%$ of all injuries. This is similar to the reported incidence of $28-54 \%{ }^{6}$

Subluxation or dissociation and fractures involving C1-C2 were observed more frequently in the younger group. Leonard et al. reported that in children aged $2-7$ years, $78 \%$ of CSls occurred in the axial region; atlanto-axial rotatory subluxation (AARS) and atlanto-occipital dislocation were the most common injuries. ${ }^{14}$

Retroclival haematoma in children may occur in three compartments: epidural, subdural and subarachnoid. Retroclival epidural haematoma may be associated with ligamentous injury, which may further result in instability at the cranio-cervical junction. ${ }^{16}$ In our study there was only one patient who had a documented ligamentous injury associated with a retroclival haematoma (superior tectorial membrane), and this did not result in cervical instability.

SCIWORA describes an acute $\mathrm{SCl}$ that results in sensory and/ or motor deficit without radiographic evidence of vertebral fracture or bony misalignment on plain X-rays or computed tomography (CT) scan. Ninety per cent of SCIWORA occurs in the paediatric population aged on average from 7 to 8 years. ${ }^{17}$ Our study confirms this finding with all children that had SCIWORA being 8 years and younger. Neurological deficit following SCIWORA can range from transient paresis to complete and permanent paralysis. ${ }^{18}$ Our patients similarly demonstrated variable neurological outcomes.

Associated injuries are common due to high velocity forces that usually cause $\mathrm{SCls}$. In this study $\mathrm{CHI}$ was the most commonly associated injury. The median ISS of patients that sustained fatal injuries was 25 , which is in accordance with the findings of Brown et al. ${ }^{6}$ who also report a mean ISS of 25 in patients with fatal injuries. In their series, as in ours, most fatal injuries were attributed to MVAs. In an audit of 22 acute injuries by Watson et al., the only child who died had an associated severe head injury. ${ }^{19}$ The mortality rate in our study was $4.5 \%$, which is much lower than in other published series. ${ }^{6,19}$ All children who died were between the ages of 3 and 5 years and had severe $\mathrm{CHIs}$.

In our study only seven patients (10\%) were treated with open reduction and internal fixation. The remainder of patients had stable injuries that healed well with simple immobilisation. Recognising unstable injury patterns is therefore essential to provide stability, but also to avoid overtreatment of stable injuries. ${ }^{14}$ The management of unstable injuries in children is the same as for the adult population, though admittedly technically more challenging due to the small size of the child's vertebrae.

There are several limitations in this study. It is a retrospective study and therefore it is possible that our population does not completely represent all CSIs in children. Our method of identifying patients also excluded those patients with transient neurological deficit but no objective evidence of CSI. Our cohort does not include children older than 13 years and we can therefore not comment on injury patterns and outcomes in the older paediatric population.

\section{Conclusion}

Our study provides insight into the epidemiology of CSIs in children $<13$ years within the South African context. CSls are rare and only occurred in $0.1 \%$ of all patients assessed at our institution following trauma. CSI should be excluded in all patients who sustained high velocity injuries such as MVAs. This is especially true for children 
under the age of 8 years and those with associated head injuries. The majority of paediatric CSI are stable injuries that can be managed conservatively; however, urgent surgical stabilisation is indicated for unstable ligamentous disruptions and fractures. CHIs caused by MVAs in young children are associated with increased mortality. Even though our patients are referred from high violence communities, no CSls were attributed to physical abuse or penetrating injury.

\section{Ethics statement}

This was a retrospective study and formal consent was not required. The ethical approval was obtained from the University of Cape Town Research committee (HREC REF: 832/2017) prior to commencement of data collection.

\section{Declaration}

The authors declare authorship of this article and that they have followed sound scientific research practice. This research is original and does not transgress plagiarism policies.

\section{Author contributions}

LN: Literature review, data collection, data interpretation and primary author.

AN: Study idea and design, supervision, editing and final approval of work.

\section{ORCID}

Noconjo L (D) http://orcid.org/0000-0001-9411-9392

Horn A (D) http://orcid.org/0000-0002-4159-6520

\section{References}

1. Leonard CJ. Cervical spine injury. Pediatr Clin N Am 2013;60:1123-37. https:// doi.org/10.1016/j.pcl.2013.06.015.

2. Hart C, Williams E. Epidemiology of spinal cord injuries: a reflection of change in South African society. Paraplegia. 1994;32(11):709-14.

3. Jones TM, Anderson PA, Noonan KJ. Pediatric cervical spine trauma. J Am Acad Orthop Surg. 2011;19:600-611.

4. Basu S. Spinal injuries in children. Front Neurol 2012;3:96. https:// doi.org/10.3389/fneur.2012.00096

5. Isaac KN, Van Niekerk A, Van As AB. Child road traffic crash at the Red Cross War Memorial Children's Hospital in Cape Town, South Africa in 1992, 2002, 2012. Int J Inj Contr Saf Promot. 2015;22(4):352-58. http://dx.doi.org/10.1080/17457300.2014.912 23.

6. Brown RL, Brunn MA, Garcia VF. Cervical spine injuries in children: a review of 103 patients treated consecutively at a level 1 pediatric trauma center. J Pediatr Surg. 2001;36(8):1107-14. https://doi. org/10.1053/jpsu.2001.25665.

7. Toh E, Arima T, Mochida J, et al. Functional evaluation using motor scores after cervical spinal cord injuries. Spinal Cord. 1998;36(7):491-96.

8. McCall T, Fasset D, Brackmeyer D. Cervical spine trauma in children: a review. Neurosurg Focus. 2006;20(2):1-8.

9. Mortazavi M, Gore PA, Chang S, et al. Pediatric cervical spine injuries: a comprehensive review. Child's Nervous System. 2011;27(5):705-17. https://doi.10.1007/s00381-010-1342-4.

10. Patel CP, Joseph JT, Daniel LM, et al. Pediatric cervical spine injuries: defining the disease. J Pediatr Surg. 2001;36(2):373-76. https://doi.org/10.1053/jpsu.2001.20720.

11. American Academy of Pediatrics. Selecting and using the most appropriate car safety seat for growing children: guidelines for counselling parents. Pediatrics. 2002;109(3):550-53. https://doi. org/10.1542/peds.109.3.550.

12. Kemp AM, Josh $\mathrm{AH}$, Man $\mathrm{M}$, et al. What are the clinical and radiological characteristics of spinal injuries from physical abuse: a systematic review. Arch Dis Child. 2010;95(5):335-60. https://doi. org/10.1136/adc.2009.169110.

13. Rooks VJ, Sister C, Burton B, et al. Cervical spine injury in child abuse: Report of two cases. Pediatric Radiology. 1998;28(3):19395. httsp://doi.org/10.1007/s002470050330.
14. Leonard JR, Jaffe DM, Kuppermann N, et al. Cervical spine injury patterns in children. Pediatrics. 2014;133:e1179-e1188. https://doi. org/10.1542/peds.2013-3505.

15. Kokoska ER, Keller MS, Rallo MC, et al. Characteristics of pediatric cervical spine injuries. J Pediatr Surg. 2001;36:100-105. https:// doi.org/10.1053/jpsu.2001.20022.

16. Kushy J, Scheurkgel MM, Clough L, et al. Neuro-imaging findings of retroclival hemorrhage in children; a diagnostic conundrum. Childs Nerv Syst. 2014;30(5):835-39. https://doi.org/10.1007/ s00381-014-2369-8.

17. Kreykes NS, Letton RW, et al. Current issues in the diagnosis of pediatric cervical spine injury. Semin Pediatr Surg. 2010;19(4):257-64. https://doi.org/10.1053/j.sempedsurg.2010. 06.002.

18. Horn A, Workman MI, Dix-Peek S, et al. Ligamentous integrity in Spinal Cord Injury without Radiographic Abnormality (SCIWORA): a case series. SA Orthop J. 2017;16(2):32-38. https://doi. org/17159/2309-8309/2017/v16n2a3.

19. Watson G, Upadhyay V. Paediatric cervical spine injuries: An audit of 22 acute injuries and literature review. Injury Extra 2005;36(11);469-74. https://doi.org/10.1016/j.injury.2005.03.024. 